\title{
Preparation and Evaluation of Natural Gum-Based Immediate Release Metformin Hydrochloride Tablet
}

\author{
Sreebash Chandra Bhowmik, Marzia Alam and Md. Saiful Islam Pathan
}

Department of Pharmacy, State University of Bangladesh, Dhanmondi, Dhaka-1209, Bangladesh

(Received: 22 February, 2018; Accepted: 29 April, 2018; Published: 31 July, 2018)

\begin{abstract}
Metformin hydrochloride is a first line BCS class III oral anti-diabetic drug used for the treatment of type 2 diabetes. The main goal of this study was to formulate, prepare and evaluate natural gum-based immediate release metformin hydrochloride tablet. Seven different formulations of compressed tablets were prepared following wet granulation process using different concentrations $(10,20,30,50,60,70$, 80 and $90 \mathrm{mg}$ ) of Aegle marmelos gum as a binder. Aegle marmelos gum is a biodegradable natural gum which is economic, easily available and found useful as tablet binder for both conventional and novel dosage forms. Other excipients used in the formulation were microcrystalline cellulose (MCC), croscarmellose sodium (CCS), maize starch, colloidal silicon dioxide (CSD), sodium starch glycolate (SSG), magnesium stearate etc. In the present study, the compressed tablets were evaluated for weight variation, thickness, hardness, friability, disintegration time and dissolution. In vitro drug release study was carried out in phosphate buffer $\left(\mathrm{pH}\right.$ 6.8) at $37 \pm 0.5^{\circ} \mathrm{C}$ with $50 \mathrm{rpm}$ using USP Dissolution Apparatus 2-Paddle method. The flowability of granules for all the batches was optimum which reflected in the bulk density and angle of repose. It can be concluded from this study that combination of Aegle marmelos as a binder with other excipients can be prospectively used in the preparation of metformin hydrochloride immediate release (IR) tablet.
\end{abstract}

Key words: Metformin hydrochloride, Aegle marmelos gum, biodegradable, flowability.

\section{Introduction}

Drug administration by oral route is probably the most appealing route for the delivery of drugs. Tablet is one of the most preferred dosage form because it is easy to manufacture, convenient to administer, accurate in dosing and more stable compared to oral liquids. Moreover, it is more tamper resistant compared to capsules (Banker et al., 1986). Factors such as the disintegration and dissolution in vivo and various physiological factors affect the bioavailability of drugs. At present, scientists are working on the formulation of rapidly disintegrating tablets. The task of developing rapidly disintegrating tablets is accomplished by using a suitable diluents and super disintegrants. Metformin, a type of biguanide is an oral hypoglycaemic agent. It is the first-line treatment option for T2D, especially in obese population with normal renal activity and those with normal kidney function (Clinical Guidelines 2005).

Limited evidence suggests metformin may prevent the cardiovascular and possibly the cancer complications of diabetes (Joint Formulary Committee, 2013; Messaoudi et al., 2011; Malek et al., 2013). Since the 1950 significant effort have been put through to acquire a better understanding of the cellular mechanism as well as the molecular mechanisms of action of metformin. Metformin acutely decrease hepatic glucose production by mildly inhibiting the mitochondrial respiratory-chain complex 1 for a transient period. The resulting decrease in hepatic glucose production causes activation of the AMP-activated protein kinase (AMPK), a cellular metabolic sensor responsible for stimulating glycolysis. This is an accepted

Correspondence to: Md. Saiful Islam Pathan; E-mail: sip@ sub.edu.bd 
mechanism of action for metformin. Restoring polycystic ovary syndrome, reducing fatty liver and lowering microvascular and macrovascular complexity associated with T2D are some of the other therapeutic activities of metformin. Metformin is also used in adjuvant treatment of cancer or gestational diabetes, and also in pre-diabetic populations as a prophylactic agent (Viollet et al., 2012).

Many natural, semi synthetic and synthetic polymers are being employed in the formulation of sustained or controlled drug delivery. In recent times natural polymers have obtained special focus because of their safety, ease of sourcing, economic nature, eco-friendliness, biocompatibility, ability to undergo chemical modifications and biodegradability (Joshi et al., 2013). Aegle marmelos is one potential source of such natural polymer. The fruit pulp of Aegle marmelos produces the gum. The tree belongs to the family Rutaceae and it is indigenous to Bangladesh. The ripe fruit pulp has a mucilaginous texture and astringent taste and it is red in colour. Vitamins A and $\mathrm{C}$, proteins, carbohydrates as well as dictamine, O-methyl fordinolandisopentylhalfordinol angelenine and marmeline are present in the fruit pulp (Joshi et al., 2013). The aim of the present study was to find out the binding prospects of Aegle marmelos gum in the formulation of immediate release tablets of Metformin hydrochloride (MFH).

\section{Materials and Methods}

\section{Materials}

MFH was obtained from Active Fine Chemicals Ltd., Dhaka, Bangladesh. Aegle marmelos gum was prepared in the pharmaceutical technology research lab, State University of Bangladesh. Maize starch was obtained from Merck Ltd. and the rest of the other reagents and chemicals were of reagent grade.

\section{Method}

Preparation and purification of Aegle marmelos (AM) gum: About $274 \mathrm{~g}$ fruit pulp of Aegle marmelos (Figure 1) was immersed in $1200 \mathrm{ml}$ distilled water for 24 hours. Then it was boiled in a water bath at $95^{\circ} \mathrm{C}$ for about 2 hours 40 minutes for slurry formation. The slurry was then cooled for 4 hours 40 minutes and refrigerated overnight. This resulted in the settlement of majority of undissolved portion. Then the clear supernatant was decanted off and centrifuged at $4000 \mathrm{rpm}$. The supernatant was heated in a water bath at $60 \pm 2^{\circ} \mathrm{C}$ until the volume reduced to one third of its original volume. The concentrated solution was cooled down to the room temperature. It was then poured into three times volume of acetone with continuous stirring. The precipitate was washed with acetone (about 4 times) repeatedly and dried at $50^{\circ} \mathrm{C}$. The dried gum was powdered to a size of $\# 60$ mesh and finally stored in air tight container.
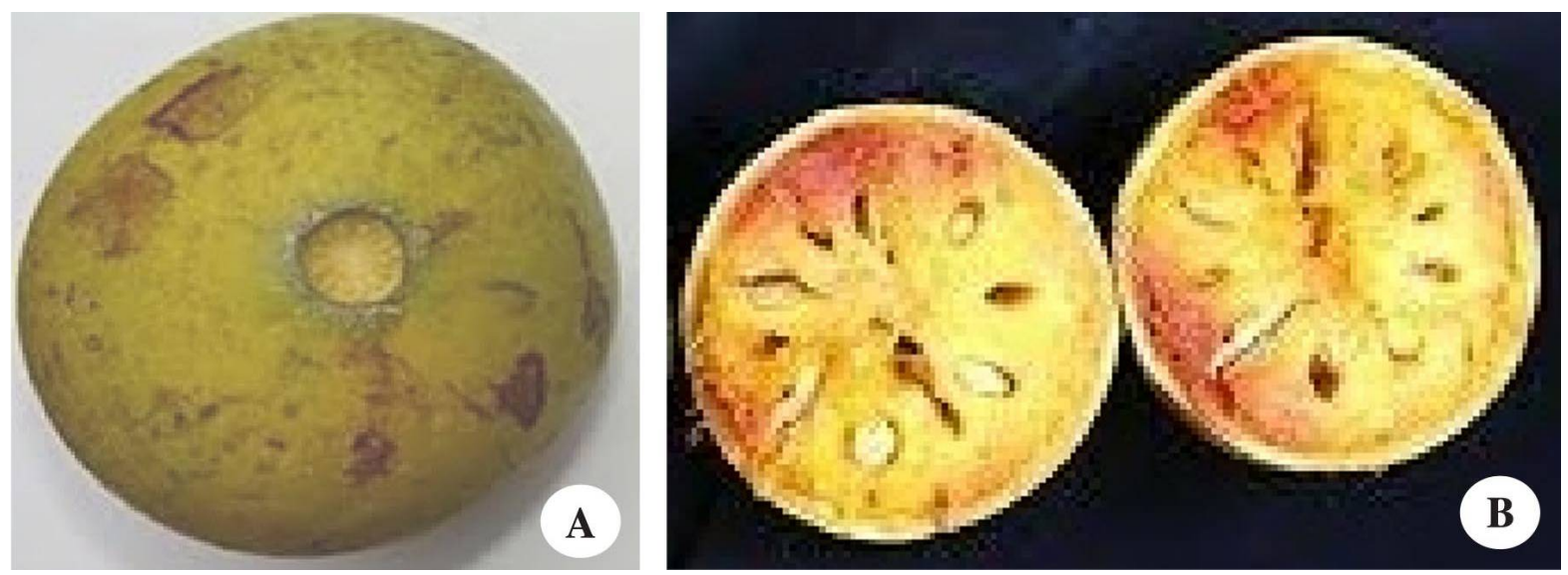

Figure 1. Aegle marmelos fruit (A), pulp (B). 
Preparation of $\mathrm{MFH}$ immediate release tablets: Since wet granulation technique ensures uniform distribution of drug as well as improves flow property of granules, wet granulation method was used for the preparation of MFH tablet. All the ingredients (metformin $\mathrm{HCl}$, aegle marmelos gum powder, MCC, CCS, Mg-stearate and Aerosil) were individually weighed accurately using calibrated electronic balance. The ingredients were sieved by \#20 mesh size. Then the following ingredients MFH, AM gum powder, MCC (50\% of total weight of MCC) were mixed for 15 minutes and granulation fluid (water: about 1-2 ml) was added for 4 minutes at a constant rate with continuous stirring. Then it was dried for 2 hours 30 minutes at $60^{\circ} \mathrm{C}$ (LOD: NMT 3.5\%) and then sieved by \#20 mesh screen. Then MCC (50\% of total weight of MCC), CCS, Aerosil and $\mathrm{Mg}$-stearate were added. A suitable blender was used to blend the screened granules at mixing speed of about $50 \mathrm{rpm}$ for approximately 5 minutes. The final blend was compressed into tablets in a suitable rotary tablet compression machine. The target weight was $775 \mathrm{mg}$ containing MFH (500 mg).

The following flow chart shows the preparation method of MFH immediate release tablets:

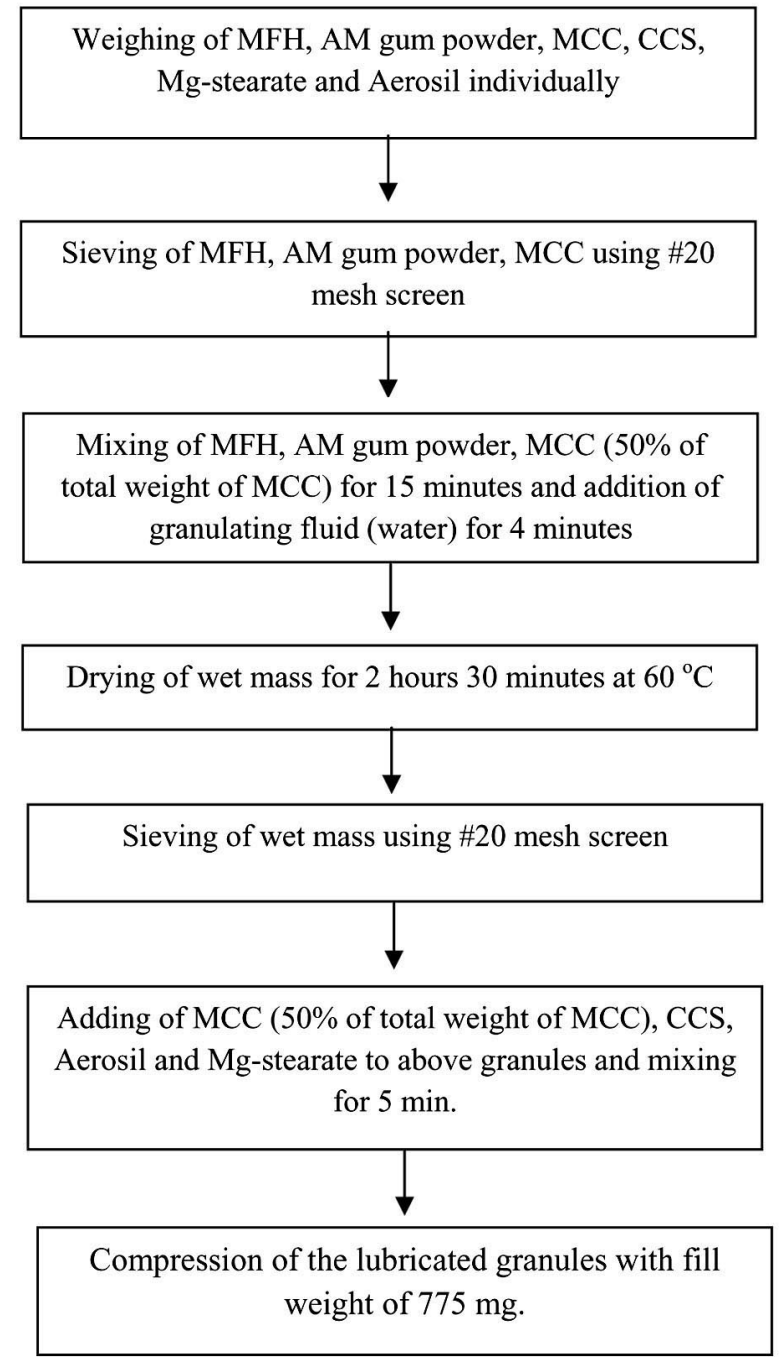


Table 1. Formulations of MFH immediate release tablet from F1 to F7

\begin{tabular}{llllllll}
\hline Ingredients & \multicolumn{7}{c}{ Formulation code } \\
\cline { 2 - 7 } & F1 & F2 & F3 & F4 & F5 & F6 & F7 \\
\hline MFH & 500 & 500 & 500 & 500 & 500 & 500 & 500 \\
AM (Aegle marmelos) gum & 10 & 20 & 30 & 50 & 60 & 70 & 80 \\
MCC (Microcrystalline cellulose-PH101) & 80 & 80 & 80 & 80 & 80 & 80 & 80 \\
CCS (Croscarmellose sodium) & 10 & 10 & 10 & 20 & 20 & 40 & 40 \\
Maize starch & 165 & 155 & 145 & 115 & 105 & 85 & 75 \\
Mg-stearate & 5 & 5 & 5 & 5 & 5 & 5 & 5 \\
Aerosil & 5 & 5 & 5 & 5 & 5 & 5 & 5 \\
Total (mg) & 775 & 775 & 775 & 775 & 775 & 775 & 775 \\
\hline
\end{tabular}

Evaluation of tablets: Following evaluations were done for the compressed tablets:

Thickness and diameter: Vernier Callipers were used to determine the thickness and diameter of the tablets. From every batch ten tablets were taken for the evaluation.

Weight variation: For weight variation test, 20 tablets from each formulation were weighed individually using an electronic balance. The individual tablet weight was compared with the average weight with the specification that not more than two individual weights deviate from the average weight by $5 \%$ and the results are shown in table 2 (USP29 Chapter <2091>).

$\%$ Deviation $=($ Average weight - Individual tablet weight $) \times 100 /$ Average weight

Hardness: The hardness of five tablets was checked using the Monsato hardness tester, average values are shown in table 2 . This was done for each formulation.

Friability: Friability of the tablets was determined using Roche friabilator. It is expressed in percentage (\%). Weight of ten tablets were taken $\left(\mathrm{W}_{\text {initial }}\right)$ and then the tablets were placed inside the friabilator. The equipment was run at $25 \mathrm{rpm}$ for 4 minutes and then the tablets were weighed again $\left(\mathrm{W}_{\text {final }}\right)$. The loss in tablet weight due to abrasion or fracture was the measure of tablet friability. \% Friability $(\mathrm{F})$ was then calculated by:

$$
\mathrm{F}=\left(\mathrm{W}_{\text {initial }}-\mathrm{W}_{\text {final }}\right) \times 100 / \mathrm{W}_{\text {initial }}
$$

Angle of repose: Funnel method was used to determine the angle of repose of the granules. The weighed granules were poured into a funnel through which the granules flowed through freely on to a plain surface. The angle of repose was calculated from the diameter of the cone formed by the granules with the help of the following equation (results recorded in table 2) (Joshi et al., 2013):

$$
\tan \theta=\mathrm{h} / \mathrm{r} \text {, or } \theta=\tan ^{-1}(\mathrm{~h} / \mathrm{r})
$$

Where, $\theta=$ angle of repose; $r=$ radius of the cone base; $\mathrm{h}=$ height of the cone

Bulk density $\left(D_{b}\right)$ : Bulk density is obtained by dividing the total mass of powder by the volume of bulk powder. Weighed powder of \#60 mesh was poured into a $10 \mathrm{ml}$ measuring cylinder and the initial volume was noted. A given weight of powder was poured into a $10 \mathrm{ml}$ measuring cylinder after passing through \#60 mesh screen and initial weight or otherwise known as bulk volume was noted. Thus the bulk density is calculated according to the following formula and the results are recorded in table 2 . The unit of bulk density is $\mathrm{g} / \mathrm{ml}$ and is given by:

$$
D_{b}=M / V_{b}
$$

Here, $\mathrm{M}=$ mass of powder, $\mathrm{V}_{\mathrm{b}}=$ bulk volume of the powder. (USP Chapter $<616>$ )

Tapped Density $\left(D_{t}\right)$ : For determination of tapped density $\left(\mathrm{D}_{\mathrm{t}}\right)$ the volume $\left(\mathrm{V}_{\mathrm{t}}\right)$ of known quantity (M) of granules was measured with the help of bulk density apparatus. It is calculated by using the following formula. The results are shown in table 2 (Joshi et al., 2013).

$$
\mathrm{D}_{\mathrm{t}}=\mathrm{W} / \mathrm{V}_{\mathrm{t}}
$$

Carr's index (\%): The difference between the tapped and bulk densities divided by the tapped 
density gave the Carr's index (\%) and the ratio expressed as a percentage. The results are shown in table 2 (Joshi et al., 2013).

Carr's index $(\%)=\left(D_{t}-D_{b}\right) / D_{t} \times 100$

Where, $\mathrm{Dt}=$ tapped density and $\mathrm{Db}=$ bulk density.

Hausner's index: The ratio of tapped density and bulk density of granules yielded the Hausner's index. The results were shown in table 2 (Joshi et al., 2013).

Hausner's index $=D_{t} / D_{b}$

Here, $D_{t}=$ tapped density and $D_{b}=$ bulk density.

Disintegration time: USP specifications were followed for the disintegration time test. Six tablets were placed in each basket of disintegration tester. The disintegration medium used was distilled water maintained at $37 \pm 0.2^{\circ} \mathrm{C}$ temperature. The tablets were considered completely disintegrated when all the particles passed through the wire mesh. The mean value of two determinations was recorded as the disintegration times. The results are shown in table 2 (Joshi et al., 2013).
In vitro drug release study: USP apparatus type II method was used for the in vitro drug dissolution studies of the prepared tablets. The dissolution medium was $900 \mathrm{ml}$ phosphate buffer at $\mathrm{pH} 6.8$ at 50 rpm. The samples were withdrawn after $30 \mathrm{~min}$ and $\%$ drug release was calculated using UV spectrophotometer at $233 \mathrm{~nm}$. Impact of binder on drug release from the different concentration is characterized by variation of drug release. The release profile of MFH (F1-F7) is shown in the table 2. The following figure shows the in vitro release of different formulations of $\mathrm{MFH}$ tablets. The F3 formulation, among F1 to F7 showed a satisfactory hardness and a drug release of $105 \%$ over 30 minutes time period. It was observed that with the variation of the concentration of AM gum, the release pattern varied. But the $\%$ release of $F 1, F 2$ and F5 formulation were found to be $99.6 \%, 98.7 \%, 100.7 \%$, respectively (Figure 2). The disintegration time of F1, F2, F5, F3 were obtained as $27 \mathrm{sec}, 26 \mathrm{sec}, 108 \mathrm{sec}$ and $28 \mathrm{sec}$, respectively. So from this consideration F3 formulation was the acceptable formulation to prepare the immediate release tablet of MFH.

Table 2. Evaluation of different formulations.

\begin{tabular}{|c|c|c|c|c|c|c|c|}
\hline \multirow{2}{*}{ Features } & \multicolumn{7}{|c|}{ Formulation code } \\
\hline & F1 & $\mathrm{F} 2$ & F3 & $\mathrm{F} 4$ & F5 & F6 & F7 \\
\hline Thickness (mm) & 5.1 & 5.1 & 5.1 & 5.1 & 5.1 & 5.1 & 5.1 \\
\hline Diameter (mm) & 13.3 & 13.3 & 13.3 & 13.3 & 13.3 & 13.3 & 13.3 \\
\hline Weight variation (mm) & $775.1 \pm 2.64$ & $772 \pm 1.73$ & $778.5 \pm 2.07$ & $773.3 \pm 1.88$ & $775.8 \pm 4.04$ & $776.1 \pm 1.63$ & $775.8 \pm 2.15$ \\
\hline Hardness $\left(\mathrm{kg} / \mathrm{cm}^{2}\right)$ & 4 & 3.8 & 5.6 & 4 & 4.5 & 4.2 & 4.2 \\
\hline Bulk density (g/ml) & 0.5 & 0.6 & 0.504 & 0.56 & 0.56 & 0.56 & 0.51 \\
\hline Tapped density (g/ml) & 0.53 & 0.6 & 0.56 & 0.68 & 0.62 & 0.623 & 0.53 \\
\hline Hausner's index & 1.05 & 1 & 1.112 & 1.21 & 1.11 & 1.113 & 1.05 \\
\hline Carr's index (\%) & 4.18 & 1.8 & 10.07 & 17.6 & 10.1 & 10.11 & 5.07 \\
\hline Angle of repose $\left(^{0}\right)$ & 33.7 & 39 & 38.66 & 35.5 & 32.9 & 34.6 & 33.7 \\
\hline Friability (\%) & $>1$ & $>1$ & $>1$ & $>1$ & $>1$ & $>1$ & $>1$ \\
\hline $\operatorname{LOD}(\%)$ & 2 & 3.3 & 2.2 & 3 & 1.2 & 2.1 & 2 \\
\hline Disintegration time (s) & 27 & 26 & 28 & 29 & 108 & 103 & 58 \\
\hline Dissolution (\%) & 99.6 & 99 & 105 & 103 & 101 & 104.5 & 101 \\
\hline
\end{tabular}




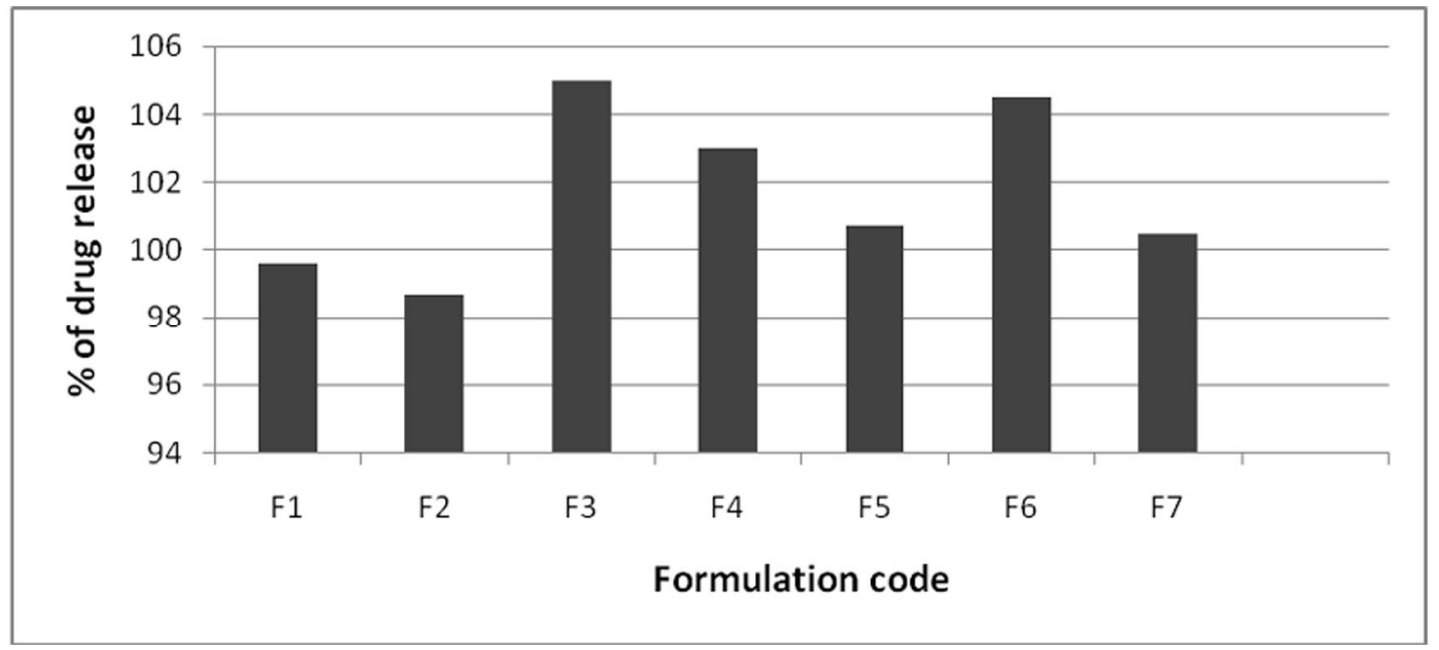

Figure 2. In vitro drug release of different formulation from F1 to F7 of MFH immediate release tablet.

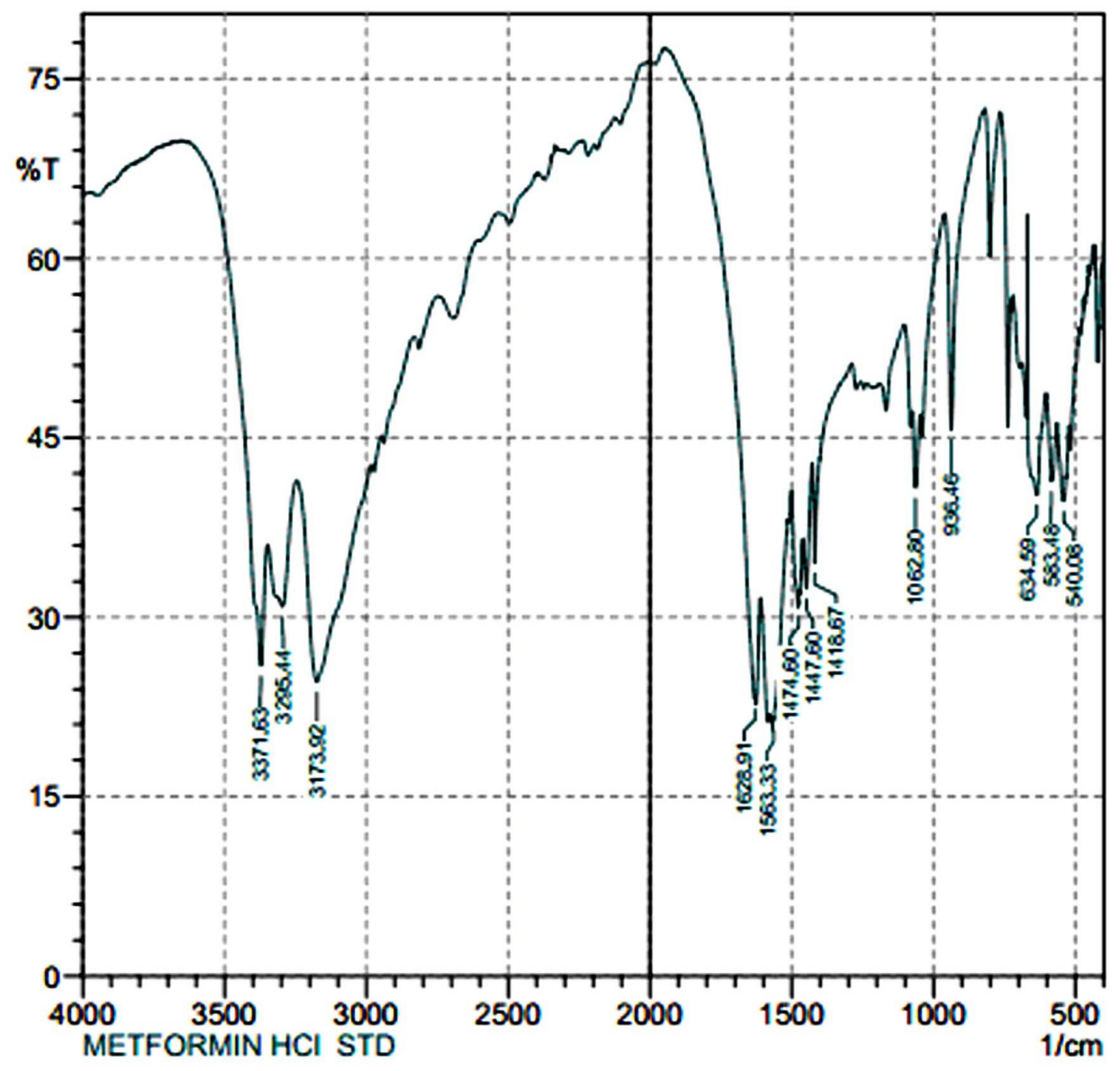

Figure 3. FTIR spectra of pure MFH. 


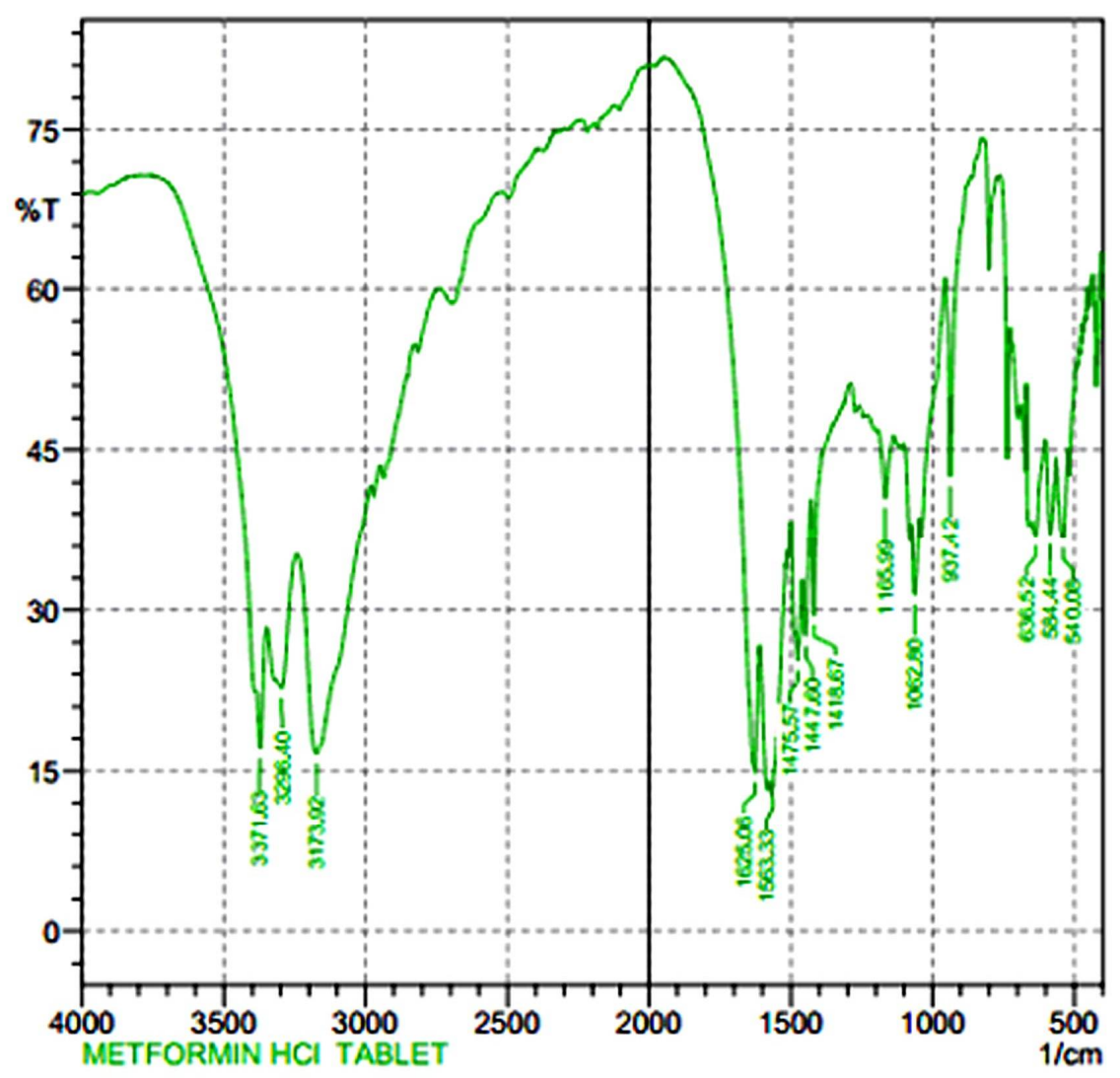

Figure 4. FTIR spectra of physical mixture of pure MFH with other excipients.

FTIR studies: FTIR spectrophotometer was used to determine drug-excipient compatibility by using MFH and physical mixtures of MFH and excipients. The IR spectra were determined by the $\mathrm{KBr}$ disc method between 4000 and $400 \mathrm{~cm}^{-1}$. FTIR studies revealed that due to the $\mathrm{N}-\mathrm{H}$ secondary stretching, MFH showed two typical bands at $4469 \mathrm{~cm}^{-1}$ and $4296 \mathrm{~cm}^{-1}$. Characteristic bands at1626 and $1567 \mathrm{~cm}^{-1}$ indicating $\mathrm{C}=\mathrm{N}$ stretching. There was no significant shift of the FTIR bands or reduction in the intensity of the bands of MFH as shown in the figures 3 and 4 .

\section{Results and Discussion}

In the current study, immediate release tablet of MFH were successfully prepared containing different concentrations of AM gum using wet granulation method. Various pre and post-compression parameters were checked for the prepared tablets.
The weights of the tablets of all batches were acceptable and the standard deviation value indicated the method was reproducible and consistent. The disintegration time and the percent of drug release were good enough. Among all the formulations, F3 formulation was the best and most acceptable formulation to prepare $\mathrm{MFH}$ immediate release tablet.

\section{Conclusion}

MFH is a poorly compressible active pharmaceutical ingredient that presents huge challenge to manufacture tablets by wet granulation method. In the present study immediate release tablets of MFH were successfully prepared using different concentrations of AM gum as a binder and croscarmellose sodium as super disintegrant by wet granulation method. From the present research it can 
be concluded that: Immediate release tablets of MFH can be prepared by wet granulation method and $\mathrm{AM}$ can be used as a binder in the formulation.

Further study on formulation optimization, drug excipients compatibility, scale up and stability study are needed to confirm the appropriateness of these formulated immediate release tablets.

\section{References}

Clinical guidelines Task Force: (http://en.wikipedia.org/ wiki/Metformin - cite_ref-3 Clinical Guidelines Task Force, International Diabetes Federation. 2005. Glucose control: oral therapy. In: Global Guideline for Type 2 Diabetes. Brussels: International Diabetes Federation, 35-8. Retrieved November 6, 2007.

Messaoudi, S.E.I., Rongen, G.A., de Boer, R.A. and Riksen, N.P. 2011. The cardioprotective effects of metformin. Curr. Opi. Lipid. 22, 445-453.

Banker, G.S. and Anderson, N.R. Tablets. In: L. Lachman, H.A. Lieberman and J.L. Kanig, Theory and Practice of Industrial Pharmacy, 3rd ed., Lea \& Febiger, Philadelphia.
USP: https://www.usp.org/sites/default/files/usp/document /harmonization/gen-chapter/bulk_density.pdf

Joint Formulary Committee. 2013. Chapter 6: Endocrine system. British National Formulary (BNF) (65 ed.). London, UK: Pharmaceutical Press. pp. 447-448. ISBN 9780857110848.

Joshi, Y., Chaudhary, R.K., and Teotia U.V.S. 2013. Formulation and evaluation of diclofenac sodium sustained release matrix tablets using Aegle marmelos Gum. IJCTPR, 1, 174-180.

Malek, M., Aghili, R., Emami, Z. and Khamseh, M.E. 2013. Risk of cancer in diabetes: The effect of metformin. ISRN Endocrin. doi:10.1155/2013/636927.

USP29-NF24 Chapter <2091>, page 3092.

Viollet, B., Guigas, B., Sanz, G.N., Leclerc, J., Foretz, M. and Andreelli, F. 2012. Cellular and molecular mechanisms of metformin: an overview. Clin. Sci. (Lond). 122, 253-270. 